\title{
Factors Affecting Endoscopic Curative Resection of Gastric Cancer in the Population-Based Screening Era
}

\author{
Yoon Gwon Mun ${ }^{1}$, Myung-Gyu Choi ${ }^{1}$, Chul-Hyun Lim ${ }^{1}$, Han Hee Lee ${ }^{1}$, Dong Hoon Kang ${ }^{1}$, Jae Myung Park ${ }^{1}$ and Kyo Young Song ${ }^{2}$ \\ ${ }^{1}$ Division of Gastroenterology, Department of Internal Medicine, College of Medicine, The Catholic University of Korea, Seoul, ${ }^{2}$ Division of \\ Gastrointestinal Surgery, Department of Surgery, Uijeongbu St. Mary's Hospital, College of Medicine, The Catholic University of Korea, \\ Seoul, Korea
}

Background/Aims: Since population-based screening for gastric cancer in Korea was implemented, endoscopic treatment of early gastric cancer has become increasingly popular. This study investigates factors affecting endoscopic curative resection of early gastric cancer in population-based screening for gastric cancer.

Methods: We retrospectively reviewed data of patients with newly diagnosed gastric cancer who underwent treatment at Seoul St. Mary's Hospital. All patients completed questionnaires about clinical information, including interval between surveillance tests for gastric cancer.

Results: Of 469 gastric cancer patients, 147 (31.3\%) had undergone curative endoscopic resection, 260 (55.4\%) had undergone curative surgical resection, and 62 (13.3\%) underwent non-curative resection or were in an inoperable state. Patients with curative endoscopic resection had fewer alarm symptoms/signs than other groups. In multivariate analysis, regular surveillance endoscopy was the only factor predicting curative endoscopic resection (odds ratio [OR], 6.099; 95\% confidence interval [CI], 2.532-14.933). In addition, patients undergoing gastric cancer screening had a significantly higher rate of endoscopic curative resection compared with subjects who had never been screened. (1-year interval: OR, 49.969; 95\% CI, 6.340-393.827, 2-year interval: OR, 15.283; 95\% CI, 1.833-127.406, over 2-year interval: OR, 10.651; 95\% CI, 1.248-90.871). Shorter screening test intervals were associated with higher rates of endoscopic curative resection.

Conclusions: Regular surveillance testing was the independent factor predicting curative endoscopic resection of gastric cancer.

Clin Endosc 2018;51:478-484

Key Words: Stomach neoplasms; Early detection of cancer; Endoscopic mucosal resection

\section{INTRODUCTION}

Gastric cancer has the second highest prevalence and the third highest mortality rate among cancers in Korea. ${ }^{1}$ Since population-based screening for gastric cancer in Korea was im-

Received: November 30, 2017 Revised: March 28, 2018

Accepted: March 31, 2018

Correspondence: Myung-Gyu Choi

Division of Gastroenterology, Department of Internal Medicine, Seoul St. Mary's Hospital, College of Medicine, The Catholic University of Korea, 222 Banpo-daero, Seocho-gu, Seoul 06591, Korea

Tel: +82-2-2258-2083, Fax: +82-2-2258-2089, E-mail: choim@catholic.ac.kr ORCID: https://orcid.org/0000-0003-4083-5187

(c) This is an Open Access article distributed under the terms of the Creative Commons Attribution Non-Commercial License (http://creativecommons.org/ licenses/by-nc/3.0) which permits unrestricted non-commercial use, distribution, and reproduction in any medium, provided the original work is properly cited. plemented in 2002, either endoscopy or gastrography is recommended every 2 years for adults aged 40 years or older. $^{2}$ Population-based screening seems to be effective in reducing mortality from gastric cancer in Korea. ${ }^{2}$ The participation rate in the Korean National Cancer Screening Program (KNCSP) was $47.3 \%$ in 2012. In previous studies, endoscopic screening was more closely associated with diagnosis of early gastric cancer (EGC) than was upper-gastrointestinal series (UGIS) screening, ${ }^{4,5}$ and the participation rate in surveillance endoscopy for gastric cancer increased from 31\% in 2002 to $73 \%$ in 2011. ${ }^{6}$ Recently, the number of patients who undergo curative treatment by endoscopic resection has also increased. ${ }^{7}$ Endoscopic resection of EGC might not be inferior to surgery with respect to overall survival. ${ }^{8}$ Moreover, early detection of gastric cancer for curative treatment by endoscopic resections result- 
ed in better prognosis and better quality of life by preserving the stomach. ${ }^{9,10}$ Prediction of curative endoscopic resection of EGC is becoming increasingly important because the general population is aging, and quality of life after treatment is becoming a greater consideration.

Therefore, it is necessary to investigate the factors predicting curative endoscopic resection of EGC. Although symptoms/ signs such as anemia and weight loss are well-known factors related to gastric cancer, ${ }^{11}$ most patients with EGC are asymptomatic. ${ }^{11}$ Patients undergoing endoscopic examination performed in accordance with alarm symptoms/signs are often found to have an advanced stage of gastric cancer and are not curable. ${ }^{12}$ Moreover, these alarm symptoms/signs are not meaningful for early detection of gastric cancer or for predicting curative endoscopic resection of EGC. ${ }^{12}$

We designed this study to investigate factors predicting curative endoscopic resection of EGC in the era of population-based screening. We also assessed the effect of surveillance testing for gastric cancer on the prognosis.

\section{MATERIALS AND METHODS}

\section{Patients}

We retrospectively reviewed collected data of patients with newly diagnosed gastric cancer who underwent treatment at Seoul St. Mary's Hospital between May 2011 and May 2016. All patients provided informed consent. We conducted a questionnaire survey and reviewed medical records of patients. Patients who refused to participate in the survey or who did not complete the questionnaire were excluded. In addition, patients who underwent surveillance testing within 6 months before the diagnosis of gastric cancer were excluded due to the probability of misdiagnosis. This study was approved by the institutional review board of Seoul St. Mary's Hospital (IRB approval number: KC11EISE0239).

\section{Data collection}

The questionnaires included questions about symptoms, social history, family history, experience participating in KNCSP, reasons for not participating in KNCSP, knowledge about KNCSP, experience of endoscopy or gastrography before diagnosis of gastric cancer, surveillance test intervals and reasons for undergoing examinations. The interval between the last and penultimate surveillance test before diagnosis of gastric cancer was classified as $>6$ months to $\leq 18$ months (1-year interval), $>18$ months to $\leq 30$ months (2-year interval) and $>30$ months (over 2-year interval).

We obtained additional data by reviewing medical records. These data included initial hemoglobin level, and Helicobacter pylori status. Specimens were taken from the gastric mucosa of each patient to confirm $H$. pylori infection status. These samples were used for histology by modified Giemsa staining, rapid urase test (CLOtest ${ }^{\circ}$; HALYARD, Zaventem, Belgium), $H$. pylori polymerase chain reaction, and $H$. pylori-specific IgG (Enzygost; Dade Behring, Marburg, Germany). Positive results in one or more tests designated the presence of $H$. pylori infection. ${ }^{13}$ The specimens of endoscopic or surgical resection from patients with gastric cancer were evaluated according to gross and histological features, tumor size, and lymph node metastasis stage as defined by the American Joint Committee on Cancer Cancer Staging Manual, 7th edition. ${ }^{14}$ We defined differentiated and undifferentiated gastric adenocarcinoma using the Japanese classification system. ${ }^{15}$

\section{Outcomes and treatment modalities}

The indications of endoscopic submucosal dissection (ESD) in our institution are as follows: (1) differentiated intramucosal adenocarcinoma without ulceration, irrespective of tumor size (2) undifferentiated intramucosal cancer $<1 \mathrm{~cm}$ without ulceration (3) absence of lymph node involvement and distant metastasis in abdominal computed tomography (4) no submucosal invasive findings using endoscopy and/or endoscopic ultrasonography. Group 1 was defined as patients who underwent endoscopic resection according to the indications as described above and pathologically confirmed curative resection. The curative resection was defined as en bloc resection, pTla, negative horizontal and vertical margin, and no lymphovascular infiltration. Group 2 was defined as patients undergoing surgical resection and pathologically confirmed curative resection. In addition, patients with beyond indications after ESD were classified into Group 2. Group 3 was defined as patients with distant metastasis or pathologically non-curative resection after surgical treatment.

\section{Statistical analysis}

We used statistical tests, such as analysis of variance, $\chi^{2}$ test, and Fisher's exact test to compare results. Descriptive statistics of continuous variables were represented as mean \pm standard deviation. We conducted logistic regression analysis to estimate the odds ratio $(\mathrm{OR})$ for associations between the treatment groups described above and factors of age, sex, first-degree relatives with gastric cancer, weight loss, and screening interval. Significant differences between the groups were defined as $p$-value $<0.05$. All statistical analyses were performed using SAS version 9.3 (SAS Institute, Cary, NC, USA). 


\section{RESULTS}

\section{Clinicopathologic characteristics}

A total of 2,868 patients were newly diagnosed and started treatment for stomach cancer at Seoul St. Mary's Hospital between May 2011 and May 2016. A total of 512 patients participated in our study and completed questionnaires. Among them, 35 patients were excluded due to incomplete questionnaires and eight patients who underwent endoscopy within 6 months before the diagnosis of gastric cancer were excluded to avoid misdiagnosis. The remaining 469 patients were enrolled in the study. Of these, 147 (31.3\%) were in Group 1, 260 (55.4\%) were in Group 2, and 62 (13.3\%) were in Group 3.

Patient age, history of first degree relatives with stomach cancer, history of previous malignancy, $H$. pylori infection status were noted. Body mass index and proportion of male patients were lower in Group 3 than Group 1 or 2. Regular gastric cancer surveillance with a 2 -year interval before the diagnosis of stomach cancer was most common in Group 1. More cases of differentiated histology were observed in Group 1, conversely, more cases of undifferentiated histology were observed in Group 3 (Table 1).

\section{Gastrointestinal and alarm symptoms/signs}

Table 2 shows gastrointestinal symptoms and alarm symptoms/signs at diagnosis. Although gastrointestinal symptoms/ signs were seen in Groups 1 and 2, they were most frequently observed in Group 3. Well-known alarm symptoms/signs associated with gastric cancer such as gastrointestinal bleeding, initial hemoglobin and clinically important weight loss (defined as unintentional weight loss of more than $5 \%$ of usual body weight over 12 months) were rarely observed in Group 1.

\section{Effect of surveillance testing on the prognosis of gastric cancer}

Multivariate analysis was performed to investigate factors

Table 1. Clinicopathologic Characteristics of Patients according to Outcome and Treatment Modality for Gastric Cancer

\begin{tabular}{|c|c|c|c|c|}
\hline & Group $1^{\text {a) }}(n=147)$ & Group $2^{\text {b) }}(n=260)$ & Group $3^{\mathrm{c})}(n=62)$ & $p$-value \\
\hline Age $($ mean \pm SD) & $62.6 \pm 10.6$ & $60.2 \pm 11.5$ & $61.2 \pm 10.4$ & 0.149 \\
\hline Sex, Male & $107(72.8 \%)$ & $162(62.3 \%)$ & $36(58.1 \%)$ & 0.048 \\
\hline BMI, kg/m² (mean \pm SD) & $23.9 \pm 2.8$ & $22.9 \pm 3.3$ & $21.5 \pm 2.8$ & $<0.001$ \\
\hline History of first degree relatives with stomach cancer & $35(23.8 \%)$ & $64(24.6 \%)$ & $10(16.1 \%)$ & 0.357 \\
\hline History of previous malignancy & $17(11.6 \%)$ & $25(9.6 \%)$ & $6(9.7 \%)$ & 0.127 \\
\hline None & $130(88.4 \%)$ & $235(90.4 \%)$ & $56(90.3 \%)$ & \\
\hline Colorectal & $8(5.4 \%)$ & $3(1.2 \%)$ & $1(1.6 \%)$ & \\
\hline Esophagus & $3(2.0 \%)$ & $1(0.4 \%)$ & $0(0.0 \%)$ & \\
\hline Lung & $1(0.7 \%)$ & $1(0.4 \%)$ & $0(0.0 \%)$ & \\
\hline Liver & $1(0.7 \%)$ & $2(0.8 \%)$ & $1(1.6 \%)$ & \\
\hline Breast & $1(0.7 \%)$ & $2(0.8 \%)$ & $2(3.2 \%)$ & \\
\hline Others & $3(2.0 \%)$ & $16(6.2 \%)$ & $2(3.2 \%)$ & \\
\hline H. pylori infection status & $88 / 141(62.4 \%)$ & $109 / 162(67.3 \%)$ & $22 / 30(73.3 \%)$ & 0.442 \\
\hline $\begin{array}{l}\text { Experience of regular gastric cancer surveillance } \\
\text { (2-yr interval) }\end{array}$ & $101(70.6 \%)$ & $128(49.6 \%)$ & $17(27.4 \%)$ & $<0.001$ \\
\hline Unknown $^{\mathrm{d})}$ & 4 & 2 & 0 & \\
\hline Differentiated stomach cancer & $139(94.6 \%)$ & $124(47.7 \%)$ & $17(27.4 \%)$ & $<0.001$ \\
\hline Stage & & & & $<0.001$ \\
\hline I & $147(100 \%)$ & $194(74.6 \%)$ & $0(0 \%)$ & \\
\hline II & $0(0 \%)$ & $28(10.8 \%)$ & $3(4.8 \%)$ & \\
\hline III & $0(0 \%)$ & $38(14.6 \%)$ & $4(6.5 \%)$ & \\
\hline IV & $0(0 \%)$ & $0(0 \%)$ & $55(88.7 \%)$ & \\
\hline
\end{tabular}

SD, standard deviation; BMI, body mass index; H. pylori, Helicobacter pylori.

${ }^{a)}$ Patients undergoing endoscopic resection and pathologically confirmed curative resection.

${ }^{b}$ Patients undergoing surgical resection and pathologically confirmed curative resection or beyond criteria of curative endoscopic resection.

${ }^{c}$ Patients with distant metastasis or pathologically non-curative resection after surgical treatment.

${ }^{\mathrm{d})}$ Patients who could not remember the cancer surveillance interval were not included $(n=6)$. 
predicting curative endoscopic resection. Patient age, sex, history of first degree relative with stomach cancer, initial hemoglobin, and weight loss did not affect the prognosis of gastric cancer. Regular surveillance testing for gastric cancer was an independent factor predicting curative endoscopic resection (OR, 6.099; 95\% confidence interval [CI], 2.532-14.933) (Table 3).

The surveillance interval, surveillance method for gastric cancer, reasons for surveillance, and knowledge of KNCSP were compared among the groups (Table 4). Experience participating in KNCSP and experience with endoscopy or gas- trography before diagnosis were more common in Group 1 than in Group 2 or Group 3. Regular check-up was the main reason for examination in Group 1, while symptoms were the main reason in Group 3. There was no difference in the surveillance method among the three groups, and approximately $90 \%$ of the patients were diagnosed with stomach cancer through endoscopy. The surveillance interval was shortest in Group 1, and more patients in Group 3 lacked experience of surveillance testing.

Logistic regression models were performed with adjustment

Table 2. Comparison of Symptoms/Signs among the Group according to Outcome and Treatment Modality for Gastric Cancer

\begin{tabular}{|c|c|c|c|c|}
\hline & Group $1^{\text {a) }}(n=147)$ & Group $2^{\text {b) }}(n=260)$ & Group $3^{c}(n=62)$ & $p$-value \\
\hline Foreign body sensation & $17(12.0 \%)$ & $31(12.3 \%)$ & $10(16.4 \%)$ & 0.653 \\
\hline Dysphagia & $11(7.8 \%)$ & $13(5.2 \%)$ & $8(13.1 \%)$ & 0.085 \\
\hline Odynophagia & $2(1.4 \%)$ & $7(2.8 \%)$ & $5(8.3 \%)$ & 0.032 \\
\hline Postprandial satiety & $43(30.7 \%)$ & $93(36.9 \%)$ & $34(55.7 \%)$ & 0.003 \\
\hline Early satiety & $17(12.1 \%)$ & $59(23.4 \%)$ & $33(53.2 \%)$ & $<0.001$ \\
\hline Heartburn & $38(27.0 \%)$ & $78(30.8 \%)$ & $21(34.4 \%)$ & 0.530 \\
\hline Epigastric pain & $21(14.9 \%)$ & $59(23.4 \%)$ & $20(32.8 \%)$ & 0.014 \\
\hline Nausea & $21(14.9 \%)$ & $39(15.5 \%)$ & $21(33.9 \%)$ & 0.002 \\
\hline Vomiting & $7(5.0 \%)$ & $25(10.0 \%)$ & $15(24.6 \%)$ & $<0.001$ \\
\hline Anorexia & $13(9.2 \%)$ & $53(21.1 \%)$ & $32(51.6 \%)$ & $<0.001$ \\
\hline Dizziness & $43(30.5 \%)$ & $72(28.2 \%)$ & $20(32.3 \%)$ & 0.783 \\
\hline Melena & $13(9.2 \%)$ & $33(13.0 \%)$ & $16(25.8 \%)$ & 0.006 \\
\hline Hematochezia & $2(1.4 \%)$ & $6(2.4 \%)$ & $2(3.3 \%)$ & 0.681 \\
\hline Hematemesis & $0(0.0 \%)$ & $5(2.0 \%)$ & $5(8.2 \%)$ & 0.001 \\
\hline Clinically important weight loss ${ }^{\mathrm{d})}$ & $18(12.2 \%)$ & $58(22.3 \%)$ & $36(58.1 \%)$ & $<0.001$ \\
\hline Initial $\mathrm{Hb}<10 \mathrm{~g} / \mathrm{dL}$ & $3(2.0 \%)$ & $18(6.9 \%)$ & $20(32.3 \%)$ & $<0.001$ \\
\hline
\end{tabular}

$\mathrm{Hb}$, hemoglobin.

${ }^{a)}$ Patients undergoing endoscopic resection and pathologically confirmed curative resection.

${ }^{b}$ Patients undergoing surgical resection and pathologically confirmed curative resection or beyond criteria of curative endoscopic resection.

${ }^{c}$ Patients with distant metastasis or pathologically non-curative resection after surgical treatment.

${ }^{\mathrm{d})}$ Unintentional weight loss of more than $5 \%$ of usual body weight over 12 months.

Table 3. Factors Predicting Rate of Curative Endoscopic Resection of Early Gastric Cancer

\begin{tabular}{|c|c|c|c|c|}
\hline \multirow{2}{*}{ Factors } & \multicolumn{2}{|c|}{ Univariate analysis } & \multicolumn{2}{|c|}{ Multivariate analysis } \\
\hline & Odds ratio $(95 \% \mathrm{CI})$ & $p$-value & Odds ratio $(95 \% \mathrm{CI})$ & $p$-value \\
\hline Age $<60$ & $1.141(0.768-1.693)$ & 0.514 & $1.506(0.673-3.369)$ & 0.319 \\
\hline Male & $1.675(1.093-2.568)$ & 0.018 & $1.054(0.479-2.321)$ & 0.896 \\
\hline $\mathrm{Hb}>10 \mathrm{~g} / \mathrm{dL}$ & $6.423(1.949-21.162)$ & 0.002 & $3.447(0.736-16.147)$ & 0.116 \\
\hline Absence of first degree relative with stomach cancer & $0.955(0.603-1.512)$ & 0.844 & $1.219(0.509-2.918)$ & 0.656 \\
\hline Absence of clinically important weight loss ${ }^{\text {a) }}$ & $2.611(1.293-5.275)$ & 0.007 & $1.488(0.671-3.300)$ & 0.328 \\
\hline Regular gastric cancer surveillance ${ }^{\mathrm{b})}$ (within $2 \mathrm{yr}$ ) & $2.902(1.903-4.425)$ & $<0.001$ & $6.099(2.532-14.933)$ & $<0.001$ \\
\hline
\end{tabular}

CI, confidence interval; $\mathrm{Hb}$, hemoglobin.

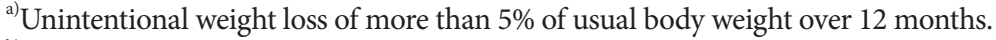

${ }^{b)}$ Patients who could not remember the cancer surveillance interval were not included $(n=6)$. 
Table 4. Comparison of Surveillance Screening among Groups according to Outcome and Treatment Modality for Gastric Cancer

\begin{tabular}{|c|c|c|c|c|}
\hline & Group $1^{\text {a) }}(n=147)$ & Group $2^{\text {b) }}(n=260)$ & Group $3^{\text {c) }}(n=62)$ & $p$-value \\
\hline Experience participating in KNCSP & $90(61.2 \%)$ & $156(60.0 \%)$ & $26(41.9 \%)$ & 0.022 \\
\hline $\begin{array}{l}\text { Experience with endoscopy or gastrography before } \\
\text { diagnosis }\end{array}$ & $133(93.0 \%)$ & $183(70.9 \%)$ & $32(51.6 \%)$ & $<0.001$ \\
\hline Reason for examination & & & & $<0.001$ \\
\hline Regular check up & $130(88.4 \%)$ & $200(76.9 \%)$ & $25(40.3 \%)$ & \\
\hline Symptom & $17(11.6 \%)$ & $60(23.1 \%)$ & $37(59.7 \%)$ & \\
\hline Surveillance method & & & & 0.134 \\
\hline Endoscopy & $118(88.7 \%)$ & $147(80.3 \%)$ & $27(84.4 \%)$ & \\
\hline Radiology & $15(11.3 \%)$ & $36(19.7 \%)$ & $5(15.6 \%)$ & \\
\hline Surveillance interval ${ }^{\mathrm{d})}$ & & & & $<0.001$ \\
\hline $1 \mathrm{yr}$ & $54(37.8 \%)$ & $61(23.6 \%)$ & $11(17.7 \%)$ & \\
\hline $2 \mathrm{yr}$ & $47(32.9 \%)$ & $67(26.0 \%)$ & $6(9.7 \%)$ & \\
\hline Over 2 yr & $32(22.4 \%)$ & $55(21.3 \%)$ & $15(24.2 \%)$ & \\
\hline None & $10(7.0 \%)$ & 75 (29.1\%) & 30 (48.4\%) & \\
\hline
\end{tabular}

KNCSP, Korean National Cancer Screening Program.

a) Patients undergoing endoscopic resection and pathologically confirmed curative resection.

${ }^{b}$ Patients undergoing surgical resection and pathologically confirmed curative resection or beyond criteria of curative endoscopic resection.

${ }^{c}$ Patients with distant metastasis or pathologically non-curative resection after surgical treatment.

${ }^{\mathrm{d})}$ Patients who did not know the cancer surveillance interval were not included $(n=6)$.

for possible confounding variables of age, sex, first degree relatives with stomach cancer, smoking history, weight loss, and initial hemoglobin to determine the effect of the interval of surveillance test on endoscopic curative resection of EGC (Table 5). Patients undergoing gastric cancer screening had a significantly higher rate of endoscopic curative resection compared with subjects who had never been screened. The ratio of endoscopic curative resection was not significantly different between surveillance intervals of 1 year, 2 years and more than 2 years. However, compared with never-screened patients, the adjusted ORs for curative endoscopic resection tended to increase as the interval of surveillance test decreased. In addition, the patients receiving 1-year surveillance screening had a significantly higher rate of endoscopic resection than patients who had no surveillance test within 3 years (OR, 12.746; 95\% CI, 4.587$35.418 ; p<0.001)$. There was a significant dose-response relationship between surveillance interval and the rate of curative endoscopic resection (Cochran-Armitage Trend Test, $p<0.0001$ ). In other words, shorter the screening test interval, higher the rate of endoscopic curative resection.

\section{DISCUSSION}

Our study investigated the factors predicting curative endoscopic resection of EGC compared with surgical or palliative
Table 5. Effect of Interval of Surveillance Testing on Curative Endoscopic Resection of Early Gastric Cancer

\begin{tabular}{lcc}
\hline $\begin{array}{l}\text { Cancer surveillance } \\
\text { interval }\end{array}$ & $\begin{array}{c}\text { Adjusted odd ratio } \\
(\mathbf{9 5 \%} \text { CI })\end{array}$ & p-value \\
\hline $1 \mathrm{yr}$ & $49.969(6.340-393.827)$ & $<0.001$ \\
$2 \mathrm{yr}$ & $15.283(1.833-127.406)$ & 0.012 \\
Over 2 yr & $10.651(1.248-90.871)$ & 0.031 \\
None & 1 & \\
\hline
\end{tabular}

Age, sex, first degree familial history of stomach cancer, clinically important weight loss, and initial hemoglobin $(<10 \mathrm{~g} / \mathrm{dL})$ were adjusted in this multivariate analysis.

Patients who could not remember the cancer surveillance interval were not included $(n=6)$.

CI, confidence interval.

treatment. Most patients with endoscopic curative resection had minimal abdominal symptoms and fewer alarming symptoms/ signs. Regular surveillance endoscopy for gastric cancer was an independent factor predicting curative endoscopic resection of gastric cancer.

Most patients with endoscopic curative resection had minimal abdominal symptoms and fewer alarm symptoms/signs, since $90 \%$ of the patients with curative endoscopic resection had regular check-ups. Anemia is considered a well-known predictor of gastric cancer, ${ }^{16}$ but it was present in only $2 \%$ of patients in Group 1 in our study. Many previous studies revealed 
that endoscopic examination after identifying symptoms did not help in earlier detection of gastric cancer. ${ }^{11,12}$ Surveillance testing by endoscopy and gastrography reduced the mortality rates associated with gastric cancer and increased the detection rate of EGC. ${ }^{17,18}$ In our study, regular surveillance testing for gastric cancer was an independent factor predicting the curative endoscopic resection of EGC. We could not measure the cancer-related mortality rate, which is the gold standard for measuring the effect of early screening and treatment. However, according to recent studies, long-term outcomes of endoscopic resection for EGC are similar to those of surgical resection, and endoscopic resection might provide better quality of life to patients. $^{9,10}$

Regular surveillance testing for gastric cancer could detect early lesions suitable for endoscopic resection and avoid invasive surgery. Population-based screening programs for gastric cancer have been established in Korea and Japan. ${ }^{4,19}$ The KNCSP recommends biennial endoscopic screening for gastric cancer in Korea, and detection of localized gastric cancer is more likely in patients who have been screened compared with never-screened patients. ${ }^{5}$ We found that a 1-year interval of surveillance testing for gastric cancer increased the rate of $\mathrm{cu}^{-}$ rative endoscopic resection of EGC compared with a 2-year interval. We expect that more frequent surveillance testing would increase both the rate of detection of EGC and the rate of curative endoscopic resection of EGC. These results are similar to those of other studies conducted in Korea. ${ }^{20-22}$ In a recent study, within the KNCSP, patients who underwent an upper endoscopy were less likely to die from gastric cancer, and no associations were found with UGIS. ${ }^{23}$ In contrast, some studies demonstrated that frequent endoscopic surveillance for gastric cancer did not reduce cancer-related mortality. ${ }^{24}$ In addition, frequent endoscopic surveillance of gastric cancer for all patients might not be cost effective. ${ }^{25}$ However, the difference in mortality rate according to interval of endoscopic surveillance for gastric cancer has not been well defined. In addition, few studies have been performed using the interval at which endoscopic resection is possible. Most of the group 1 patients underwent screening for regular check-up, not due to alarming symptoms. Some patients of group 1 might have been at high risk and may have been recommended to visit at 1 year intervals. However, we did not investigate the reasons for testing at more frequent annual intervals than national guidelines. Further refinement of the high-risk group is required for gastric cancer that requires a shorter interval of surveillance testing, such as patients with atrophic gastritis or intestinal metaplasia, family history of gastric cancer and previously diagnosed gastric cancer. ${ }^{26,27}$ Further evaluation is necessary regarding the cost-effectiveness of more frequent endoscopic surveillance for gastric cancer.
This study has several limitations. First, because of the staged work-up through various pathways at our institution prior to treatment, we could obtain informed consents of only 512 of the 2,868 patients (17.9\%). Most of the enrolled patients were those who visited internal medicine department. This study population did not represent all the patients diagnosed with gastric cancer at our hospital, which might lead to a bias. Second, we have included patients who belong to the expanded criteria for ESD. The selection of treatment options for these patients has not yet been established.

In conclusion, regular surveillance testing was an independent factor predicting curative endoscopic resection of gastric cancer. More frequent surveillance testing could help in early detection of gastric cancers, with a chance of endoscopic curative resection.

\section{Conflicts of Interest}

The authors have no financial conflicts of interest.

\section{REFERENCES}

1. Jung KW, Won YJ, Oh CM, Kong HJ, Lee DH, Lee KH. Cancer statistics in Korea: incidence, mortality, survival, and prevalence in 2014. Cancer Res Treat 2017;49:292-305.

2. Choi KS, Suh M. Screening for gastric cancer: the usefulness of endoscopy. Clin Endosc 2014;47:490-496.

3. Suh M, Song S, Cho HN, et al. Trends in participation rates for the National Cancer Screening Program in Korea, 2002-2012. Cancer Res Treat 2017;49:798-806.

4. Choi KS, Jun JK, Suh M, et al. Effect of endoscopy screening on stage at gastric cancer diagnosis: results of the National Cancer Screening Programme in Korea. Br J Cancer 2015;112:608-612.

5. Choi KS, Jun JK, Park EC, et al. Performance of different gastric cancer screening methods in Korea: a population-based study. PLoS One 2012;7:e50041.

6. Lee S, Jun JK, Suh M, et al. Gastric cancer screening uptake trends in Korea: results for the National Cancer Screening Program from 2002 to 2011: a prospective cross-sectional study. Medicine (Baltimore) 2015;94:e533.

7. Jung HY. Endoscopic resection for early gastric cancer: current status in Korea. Dig Endosc 2012;24 Suppl 1:159-165.

8. Pyo JH, Lee H, Min BH, et al. Long-term outcome of endoscopic resection vs. surgery for early gastric cancer: a non-inferiority-matched cohort study. Am J Gastroenterol 2016;111:240-249.

9. Ryu SJ, Kim BW, Kim BG, et al. Endoscopic submucosal dissection versus surgical resection for early gastric cancer: a retrospective multicenter study on immediate and long-term outcome over 5 years. Surg Endosc 2016;30:5283-5289.

10. Kim SG, Ji SM, Lee NR, et al. Quality of life after endoscopic submucosal dissection for early gastric cancer: a prospective multicenter cohort study. Gut Liver 2017;11:87-92.

11. Bowrey DJ, Griffin SM, Wayman J, Karat D, Hayes N, Raimes SA. Use of alarm symptoms to select dyspeptics for endoscopy causes patients with curable esophagogastric cancer to be overlooked. Surg Endosc 2006;20:1725-1728.

12. Axon A. Symptoms and diagnosis of gastric cancer at early curable stage. Best Pract Res Clin Gastroenterol 2006;20:697-708.

13. Yanaoka K, Oka M, Mukoubayashi C, et al. Cancer high-risk subjects identified by serum pepsinogen tests: outcomes after 10-year follow-up 
in asymptomatic middle-aged males. Cancer Epidemiol Biomarkers Prev 2008;17:838-845

14. Edge S, Byrd DR, Compton CC, Fritz AG, Greene F, Trotti A. AJCC cancer staging handbook : from the AJCC cancer staging manual. 7th ed. New York (NY): Springer-Verlag New York; 2010.

15. Japanese Gastric Cancer Association. Japanese classification of gastric carcinoma: 3rd English edition. Gastric Cancer 2011;14:101-112.

16. Vakil N, Moayyedi P, Fennerty MB, Talley NJ. Limited value of alarm features in the diagnosis of upper gastrointestinal malignancy: systematic review and meta-analysis. Gastroenterology 2006;131:390-401; quiz 659-660.

17. Hamashima C, Ogoshi K, Okamoto M, Shabana M, Kishimoto T, Fukao A. A community-based, case-control study evaluating mortality reduction from gastric cancer by endoscopic screening in Japan. PLoS One 2013;8:e79088

18. Lee KJ, Inoue M, Otani T, Iwasaki M, Sasazuki S, Tsugane S. Gastric cancer screening and subsequent risk of gastric cancer: a large-scale population-based cohort study, with a 13-year follow-up in Japan. Int J Cancer 2006;118:2315-2321.

19. Hamashima C, Shibuya D, Yamazaki H, et al. The Japanese guidelines for gastric cancer screening. Jpn J Clin Oncol 2008;38:259-267.
20. Nam SY, Choi IJ, Park KW, et al. Effect of repeated endoscopic screening on the incidence and treatment of gastric cancer in health screenees. Eur J Gastroenterol Hepatol 2009;21:855-860.

21. Nam JH, Choi IJ, Cho SJ, et al. Association of the interval between endoscopies with gastric cancer stage at diagnosis in a region of high prevalence. Cancer 2012;118:4953-4960.

22. Kim YS, Park HA, Kim BS, Yook JH, Lee MS. Efficacy of screening for gastric cancer in a Korean adult population: a case-control study. J Korean Med Sci 2000;15:510-515.

23. Jun JK, Choi KS, Lee HY, et al. Effectiveness of the Korean National Cancer Screening Program in reducing gastric cancer mortality. Gastroenterology 2017;152:1319-1328.e7.

24. Riecken B, Pfeiffer R, Ma JL, et al. No impact of repeated endoscopic screens on gastric cancer mortality in a prospectively followed Chinese population at high risk. Prev Med 2002;34:22-28.

25. Lin JT. Screening of gastric cancer: who, when, and how. Clin Gastroenterol Hepatol 2014;12:135-138.

26. Yoon H, Kim N. Diagnosis and management of high risk group for gastric cancer. Gut Liver 2015;9:5-17.

27. Choi IJ. Endoscopic gastric cancer screening and surveillance in highrisk groups. Clin Endosc 2014;47:497-503. 